\title{
Emergency Power Supply using Flywheel and Doubly Fed Induction Generator
}

\author{
Noriyuki Kimura ${ }^{1}$, Makoto Sonoda ${ }^{1}$, Toshimitsu Morizane ${ }^{1}$, Katsunori Taniguchi ${ }^{1}$ and Fujio Kurokawa ${ }^{2}$ \\ ${ }^{1}$ Osaka Institute of Technology (Osaka, Japan) \\ ${ }^{2}$ Nagasaki University (Nagasaki, Japan) \\ E-mail:kimura@ee.oit.ac.jp
}

\begin{abstract}
An emergency power supply (EPS) using an induction generator with a fly-wheel energy storage is investigated. Two different exciting system for the wounded rotor winding have been investigated. The principles of the operation and experimental results are shown. The results of start-up and steady state condition indicate that the inverter rating of the doubly fed induction generator is reduced fairly.
\end{abstract}

\section{INTRODUCTION}

In this paper, the emergency power supply (EPS) using an induction generator with a flywheel energy storage is described. However, an electric battery comparatively has a short life time, and maintenance check is necessary for security of reliability, and bad influence to environment at the time of the disposal is pointed out, too.

The lifetime of the flywheel is longer than that of the battery, and the flywheel does not cause any pollution at replacement, that is, the influence over the environment in case of abandonment is small. Therefore we have proposed uninterruptible power supply by energy storage with flywheel, instead of battery [3].

Usually, a commercially utilized EPS with flywheel at present is using a set of a rectifier and an inverter, because the output frequency from the synchronous generator changes along with the rotating speed. The required rating of the inverter is as much as the load. Then the cost is not as small as a system using a battery.

Therefore, the authors have been investigating a system using an induction generator for the reduction of the rating and the cost of the inverter. The induction generator used here is wounded rotor winding type, and variable frequency excitation of the secondary winding has been investigated.

\section{SLIP RECOVERY INDUCTION GENERATOR SYSTEM}

The authors have proposed the slip-power recovery induction generator with a battery-inverter power supply system in Figure 1 to build the long durable uninterruptible power supply[1,2]. Voltage source converter (VSC) is necessary to excite the induction machine.

The suggested system inherits the merits of both of the battery UPS and the induction generator. Small battery is used for the UPS energy source only for short instance until the engine - generator speeds up substantially and then the latter supplies all the power necessary.
The engine - generator system is the application of static Scherbius system and can generate the constant frequency even when the speed of the prime mover changes largely. The induction generator needs three phase power source which supplies power to its armature windings.

Previously proposed system with batteries is using chopper to control the 2nd winding ( the rotor winding) current of the induction generator, as shown in Figure 1.

Another previously proposed system with flywheel is shown in Figure 2. It is also using chopper and needs extra cage rotor type induction motor. While the rotating energy is being stored by the induction motor (the cage rotor type of the synchronous rotating speed at $3600 \mathrm{rpm}$ ) which connected with the flywheel, and induction generator ( the wounded rotor winding type of the synchronous rotating speed at $1800 \mathrm{rpm}$ ) supplies power to the load if needed.

The number of the poles of the induction generator is twice of the motor and the generator operation can be possible at the same rotating speed (between 1800 and $3600 \mathrm{rpm}$ ) of the induction motor while storing the energy.

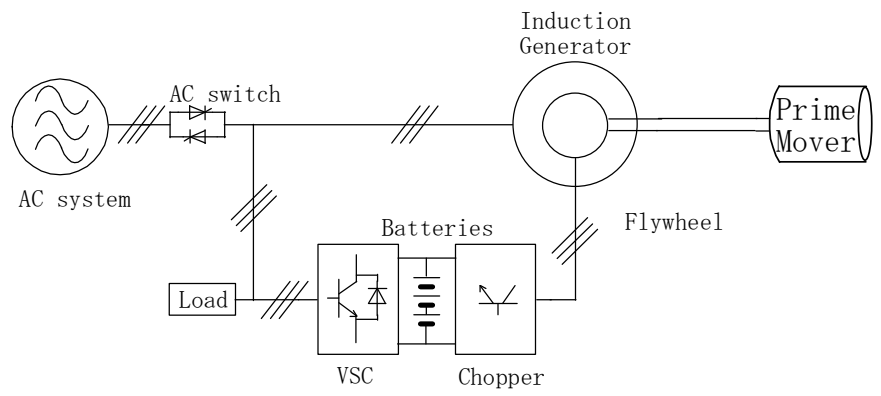

Figure 1. Slip-power recovery induction generator system with batteries

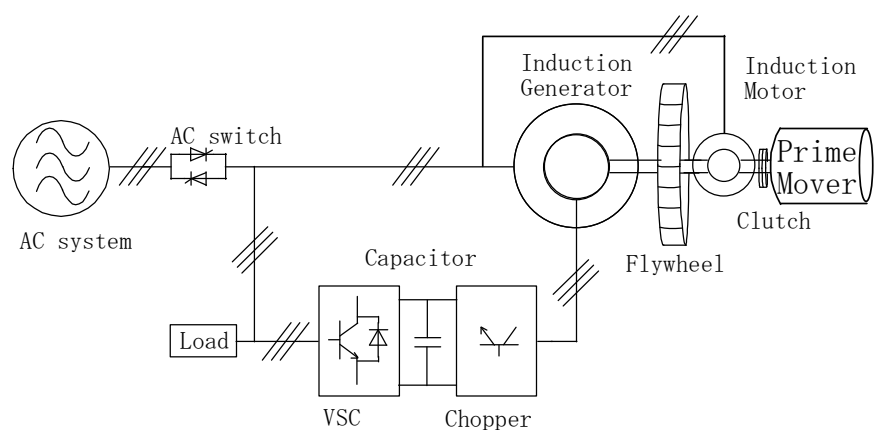

Figure 2. Slip-power recovery induction generator system with flywheel 


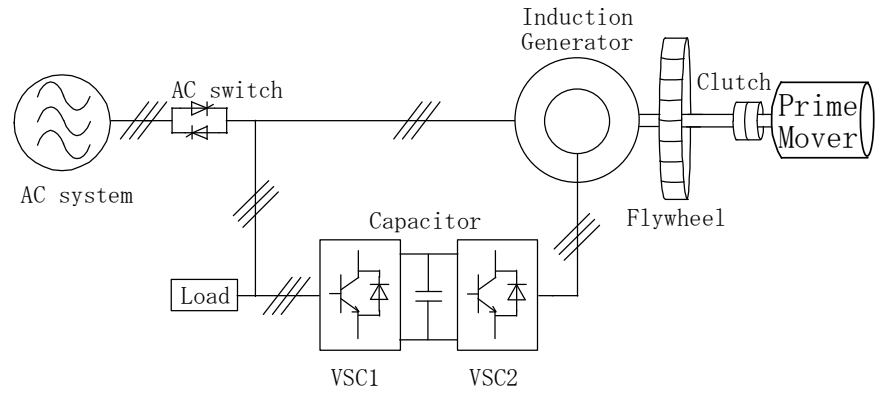

Figure 3. Proposed emergency power supply with the flywheel

\section{THE CONFIGURATION OF EMERGENCY POWER SUPPLY WITH FLYWHEEL}

The configuration of proposed emergency power supply with the flywheel is shown in Figure 3. Two different configurations, System A and System B, are investigated here. The difference is the excitation method of the induction generator.

This system uses one induction machine for both of the induction motor and the induction generator by using an inverter for exciting the 2nd winding (rotor) of the induction machine. The operation of the system is as follows.

Storing and generation of energy is accomplished by one induction machine (wounded 2nd winding type: the rated rotating speed of $1800 \mathrm{rpm}$ ) which connected with the flywheel. When the energy is being stored, the inverter controls the frequency of 2 nd winding current to make the slip to be positive. In case of power generation, the inverter controls a frequency to make the slip to become negative. Controlling a slip by using the inverter excitation, one induction machine can have motor mode and generator mode at the same rotating speed (between $0-3600 \mathrm{rpm}$ ).

(1) The energy is stored to the flywheel, by using an induction machine as the electric motor operation mode. In the standby mode, it is rotating at the constant speed of nearly $3600 \mathrm{rpm}$. The frequency of the inverter is controlled to make the slip to become positive.

(2) The frequency of the inverter is controlled to make the slip to become negative. When the voltage of the utility line is fallen, the inverter is controls its frequency to make the slip to become negative. This moment, short power interruption occurs. After that, it supplies electric power to the load from the induction generator using the energy of the flywheel. Voltage with required frequency is output from the inverter. the capacitor on the DC side is stored up by the output power from the 2 nd windings of the induction generator.

(3) When the longer power supply is necessary, an engine must be started. The operation with the engine is as same as System A.

\section{THE POWER FLOW OF DFIG}

\section{A. Active Power flow}

The power flow of a secondary excitation generator is shown in Figure 4.
It is considered as the mechanical axis input $P_{T}$ of external power. It is considered as the stator active power $P_{1}$ (an output is positive). It is considered as the rotor active power $P_{2}$ (an input is positive). It is considered as the conversion power $P_{21}$ from a rotor to a stator.

Stator copper loss, iron loss, and machine loss of an external power supply are neglected.

The relation of equation (10) is realized in approximation.

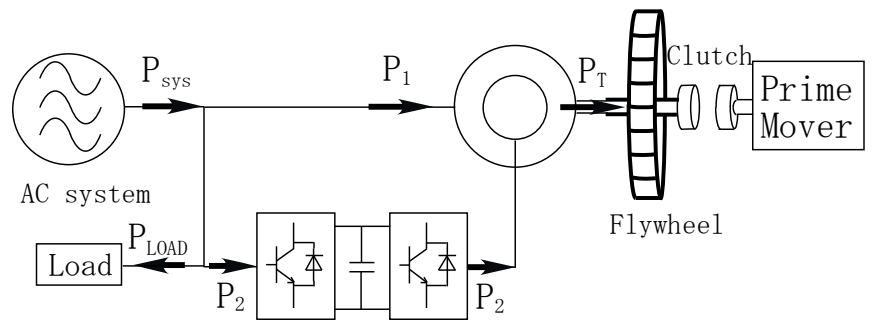

(a) Mode (1): Energy storing to flywheel (Variable speed, prime mover disconnected and stopped)

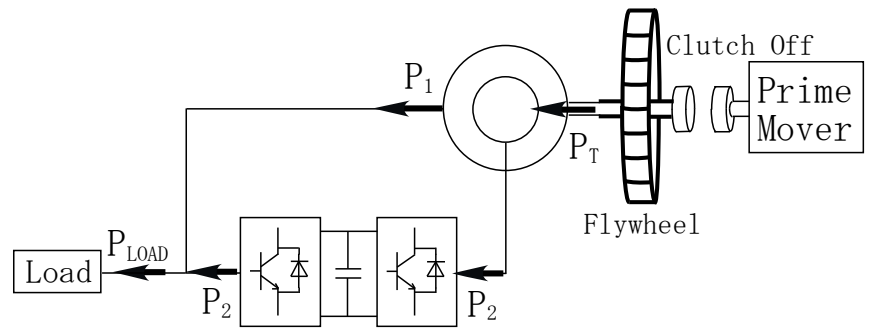

(b) Mode (2): Energy supplying by flywheel (Variable speed, prime mover disconnected and starting)

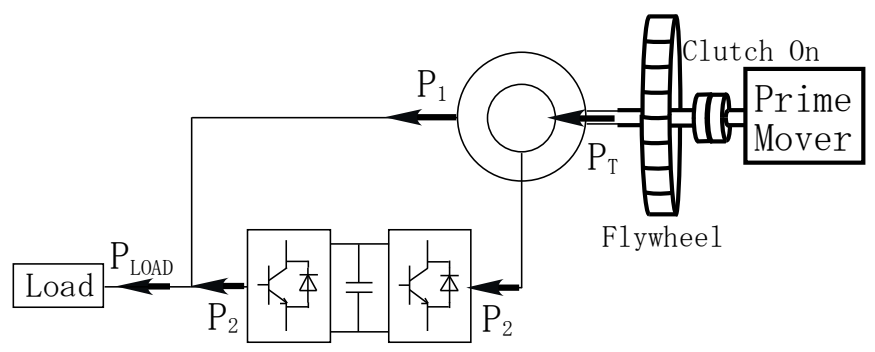

(c) Mode (3): Energy supplying by prime mover (Constant speed, prime mover connected)

Figure 4. Schematic diagram of the experimental setup

$$
\left.\begin{array}{l}
P_{1}=P_{T}+P_{2} \\
P_{T}=P_{1}-P_{2}=(1-s) P_{1} \\
s \cdot P_{1}=P_{2}
\end{array}\right\} \ldots \text { (1) }
$$

equation (1) from

$$
s=\frac{P_{2}}{P_{1}}=\frac{P_{2}}{P_{T}+P_{2}} \ldots
$$


1) $P_{2}>0$

This condition is $s=\frac{P_{2}}{P_{T}+P_{2}}>0$.

It becomes a secondary excitation generator which rotates with asynchronous speed.

2) $P_{2}=0$

This condition is $s=0$.

It is equivalent to the usual induction machine by the case where there is no input of the second side.

3) $P_{2}<0$

This condition is $s<0$.

It becomes a secondary excitation generator which rotates with super-synchronous speed. The power flow at this time is shown in Fig. 6.

Here, the secondary loss $P_{\text {LOSS }}$ is neglected.

\section{B. Reactive power flow}

Next, the reactive power flow of an induction machine is described. Set excitation reactive power of an induction machine to $Q_{m}$, and let conversion of the reactive power from $Q_{1}$ and a rotation child to a stator be $Q_{21}$ and the rotation child reactive power $Q_{2}$ for stator reactive power. (Direction makes delay reactive power positive and expresses it in Figure 5)

It will be set to $Q_{1}=0$ (power-factor 1 ), if reactive power is poured in from the rotation child side so that it may be now set to $Q_{21}=Q_{m}=s Q_{2}$.

Since the control of reactive power can output big reactive power from the stator side with reactive power with smaller controlling from the low rotation child side of frequency, it is efficient. In the case of a slip $s=0$, the reactive power of infinite size can be supplied from the stator side. Therefore, the synchronous generator which operate direct-current excitation can output big reactive power by controlling field system voltage.

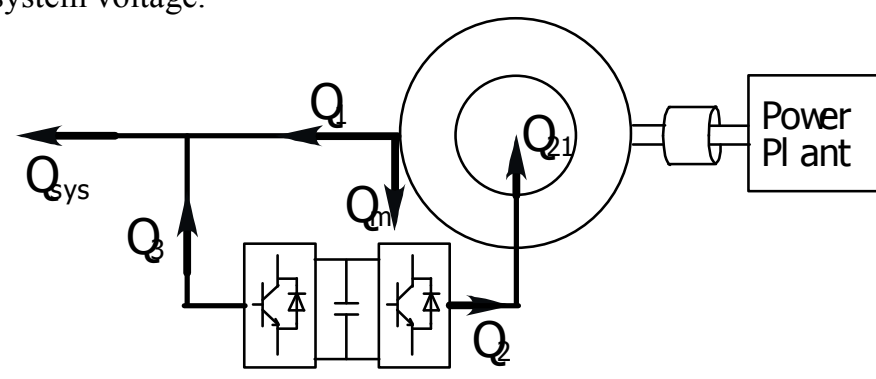

Figure 5. The reactive-power flow of DFIG

\section{CONTROL SCHEME}

The power converter usually includes the power control, the rotor side current control, dc link dynamics, the grid side current control and the PWM scheme.

Excitation is added to a secondary winding with the inverter connected to the secondary side. It requires for a rotor $\mathrm{d}-\mathrm{q}$ axis current control target from an equation (8) from the control set point of stator effective power and stator reactive power.

The control system for VSC1 and 2 are shown in Figure 6 and 7, respectively. The fundamentals are well known d-q axis vector control [4].

In operating mode (1), the active power is absorbed from the utility system to the flywheel rotating power. VSC2 is controlled to have the active power absorbed to the flywheel by changing the exciting amplitude, frequency and phase. VSC1 is controlled to keep the dc side voltage constant.

In operating mode (2), the active power is supplied from the flywheel to the load. VSC1 is controlled to keep the dc side voltage and ac output voltage constant. Therefore, it decides the output active and reactive power possible to supply. Then VSC2 is controlled to supply the extra active power required to the load from the flywheel by changing the exciting amplitude, frequency and phase.

\section{THE EXPERIMENTAL SETUP OF THE INDUCTION GENERATOR SYSTEM}

The induction power generation system for EPS with a flywheel is investigated experimentally. The experimental setup of the system is shown in Figure 3.

A flywheel is simulated by the DC motor. The load is the RLC load equipment of 3 phase. The reactors (ACL:1.2mH) and capacitors (ACC:10uF) are installed between the inverter and the load to improve the current controllability and to suppress the higher harmonics.

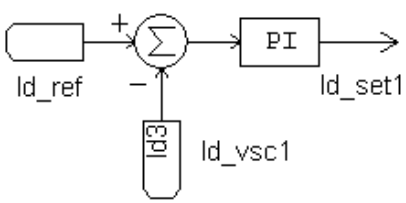

(a)

Id controller

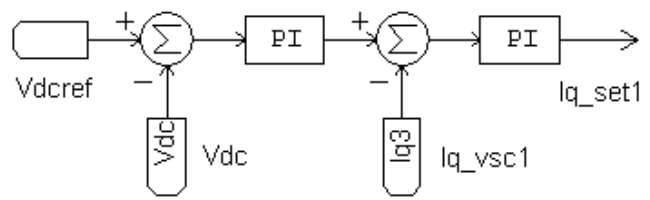

(b) Iq controller

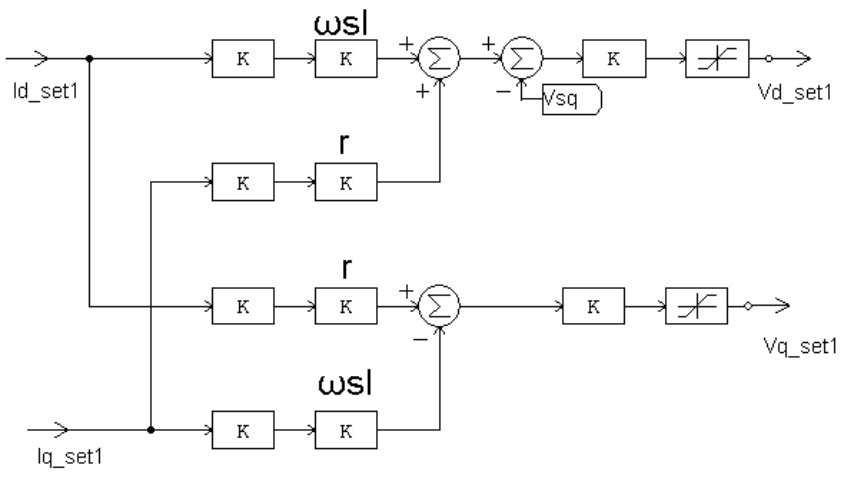

(c) Vd, Vq controller

Figure 6. VSC1 controller diagram of proposed system 


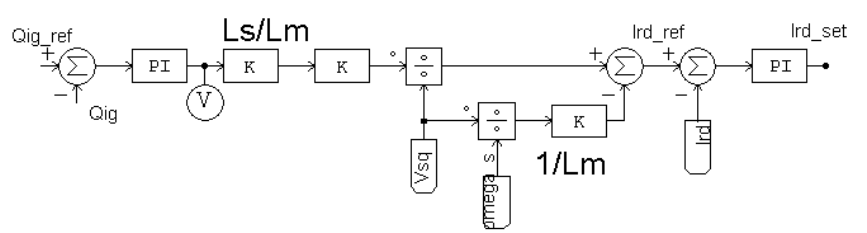

(a) Id controller

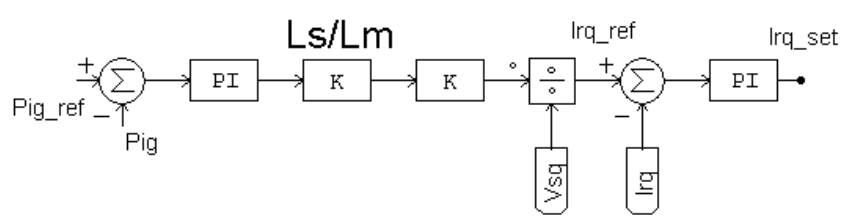

(b) Iq controller

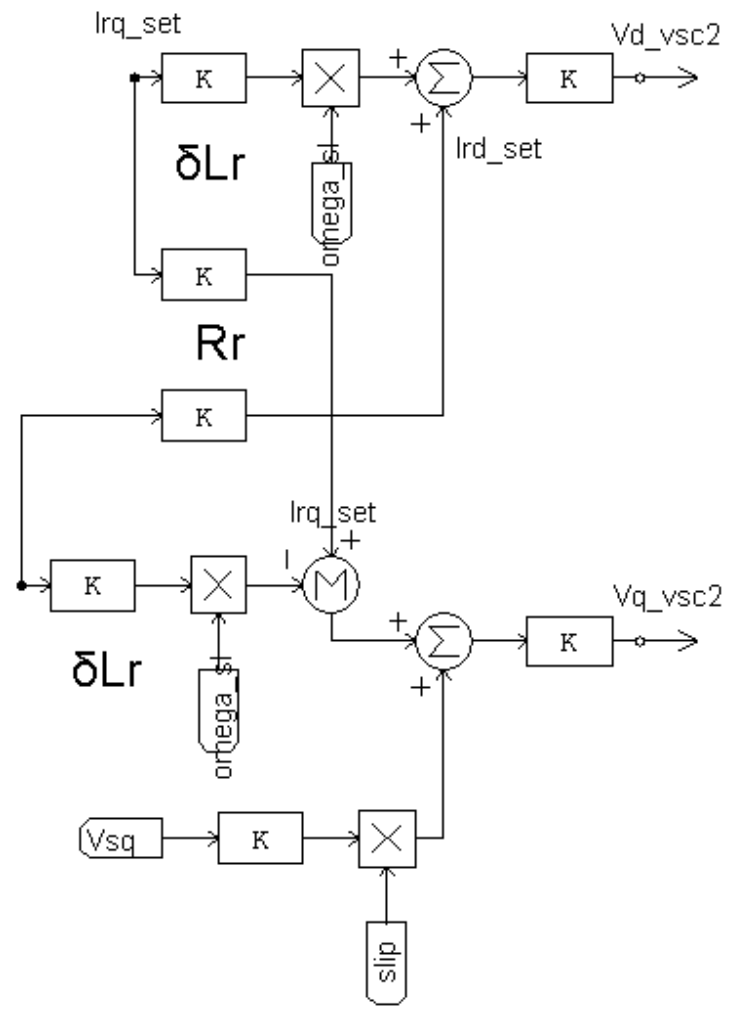

(c) Vd, Vq controller

Figure 7. VSC2 controller diagram of proposed system

In the system of Figure 8, a current of rotor windings of the induction generator is directly supplied from the inverter. Experiments of start-up and steady state operation are performed with this system. In the complete system, the voltage converter system with VSC1 and VSC2 are controlled to keep the dc side capacitor voltage. However, in this experiment, the dc side capacitor is replaced by the dc power supply of constant dc voltage to measure the excitation effect of the induction machine only.

Since the rated rotating speed of the direct current motor was $1800[\mathrm{rpm}], 40 \mathrm{~Hz}$ is used ( the synchronous rotating speed: $1200[\mathrm{rpm}]$ ) as the system frequency. Therefore, the reactive power consumption increases inversely proportional to the frequency compared with $60 \mathrm{~Hz}$ because the impedance is proportional to the frequency.

TABLE I I EXPERIMENTAL DEVICE PARAMETER

\begin{tabular}{|c|c|c|}
\hline \multicolumn{3}{|l|}{ Induction generator } \\
\hline Synchronous rotation speed & 1800 & {$[\mathrm{rpm}]$} \\
\hline Rated voltage & 100 & {$[\mathrm{~V}]$} \\
\hline Rated frequency & 60 & {$[\mathrm{~Hz}]$} \\
\hline Primary resistance & 0.54 & {$[\Omega]$} \\
\hline Primary reactance & 1 & {$[\Omega]$} \\
\hline Magnetizing resistance & 3.15 & {$[\Omega]$} \\
\hline Rated output & 800 & {$[\mathrm{~W}]$} \\
\hline Pole number & 4 & \\
\hline Secondary resistance & 0.81 & {$[\Omega]$} \\
\hline Secondary reactance & 1.03 & {$[\Omega]$} \\
\hline Magnetizing reactance & 28.1 & {$[\Omega]$} \\
\hline $\mathrm{AC}$ reactor & 1.2 & {$[\mathrm{mH}]$} \\
\hline
\end{tabular}

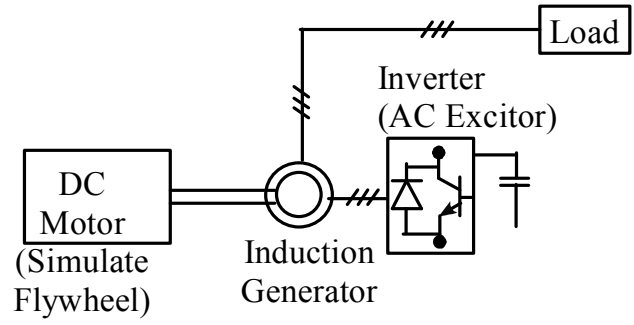

Figure 8. Schematic diagram of the experimental setup

\section{THE EXPERIMENTAL RESULTS OF PROPOSED SYSTEM}

Experiments are performed for an induction power generation system for the emergency power supply with a flywheel using configuration of proposed system in Figure 8. It is assumed that the EPS has been separated from the utility system after the electric power system fault at the initial condition and the starting up time of the voltage and the current are measured in case of inverter start-up. The results are shown in Figure 9.

Load voltage was established within 1 cycle and about $10 \%$ of overvoltage occurred but were reaching an regular condition approximately at $20 \mathrm{mS}$ after inverter start-up. The start up speed is sufficiently fast. An inverter current in the early stages never exceeds the value of the steady state operation. 
TABLE II. THE EXPERIMENT CONDITION ( SYSTEM A, THE SYSTEM WITH A CHOPPER AT THE 2ND WINDING )

(with the reactive power compensation).

Starting up to the capacitive load without chopper control.

\begin{tabular}{|l|r|l|}
\hline Load voltage & 80 & {$[\mathrm{~V}]$} \\
\hline Load real electric power & 350 & {$[\mathrm{~W}]$} \\
\hline Load apparent electric power & 360 & {$[\mathrm{VA}]$} \\
\hline Load frequency & 40 & {$[\mathrm{~Hz}]$} \\
\hline Inverter real electric power & 35 & {$[\mathrm{~W}]$} \\
\hline Inverter apparent electric power & 155 & {$[\mathrm{VA}]$} \\
\hline Inverter frequency & 20 & {$[\mathrm{~Hz}]$} \\
\hline Induction machine rotating speed & 1780 & {$[\mathrm{rpm}]$} \\
\hline
\end{tabular}

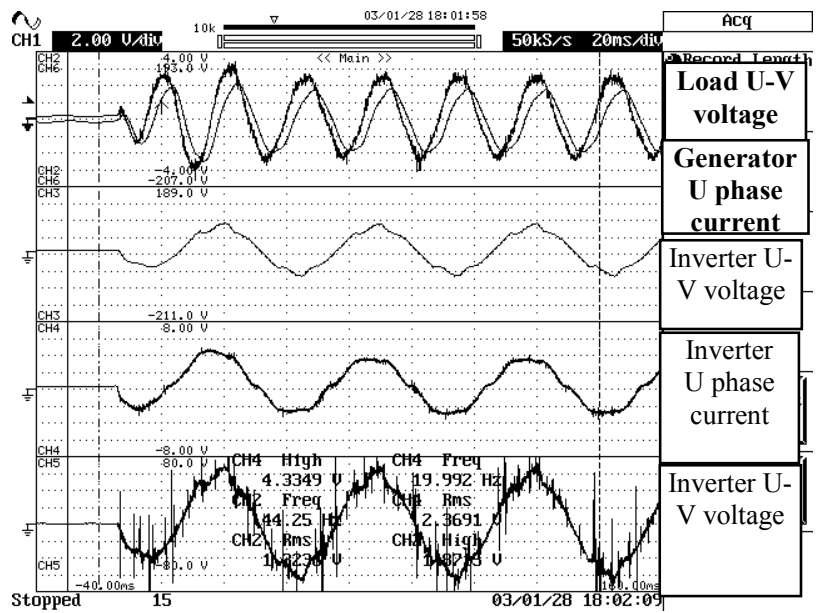

Figure 9. The start-up experiment of System B ( rotor winding is excited by alternating current)

CH.2 Rotor U phase current (8A Full Scale), CH.6: UV line-to-line voltage of the inverter (400V Full Scale),

CH.3: UV line-to-line voltage at the load (400V Full Scale),

CH.4 Inverter U phase current (16A Full Scale),

CH.5: UV line-to-line voltage at the rotor (160V Full Scale)

The rating of the inverter can be decided by the steady state operation from this fact. In case of steady state operation, the voltage and the current waveform are smooth.

\section{Simulation of Proposed System}

Simulation was performed by using PSIM 8.0. Figure 10 shows the simulation results of operation mode (1) when the flywheel is absorbing and storing the energy.

In this simulation, the inertia of the flywheel is reduced largely to make the simulation time shorter. It takes more than several ten seconds for realistic system. The modulation factor of the rotor side VSC is kept constant and consequently the current is decreasing according to the frequency increase. To accelerate the flywheel in short period, proper control of the rotor current is necessary.
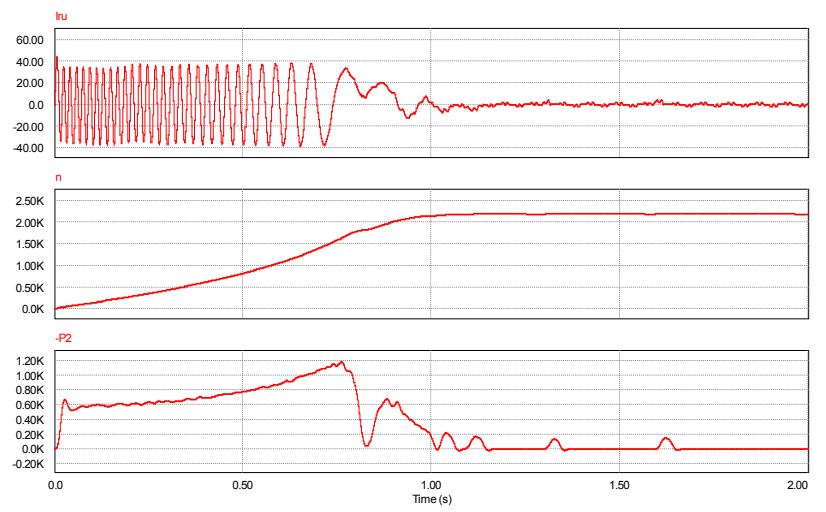

Figure 10. Energy storing simulation

From Upper to Lower: Rotor current, Rotating speed of flywheel, Input power
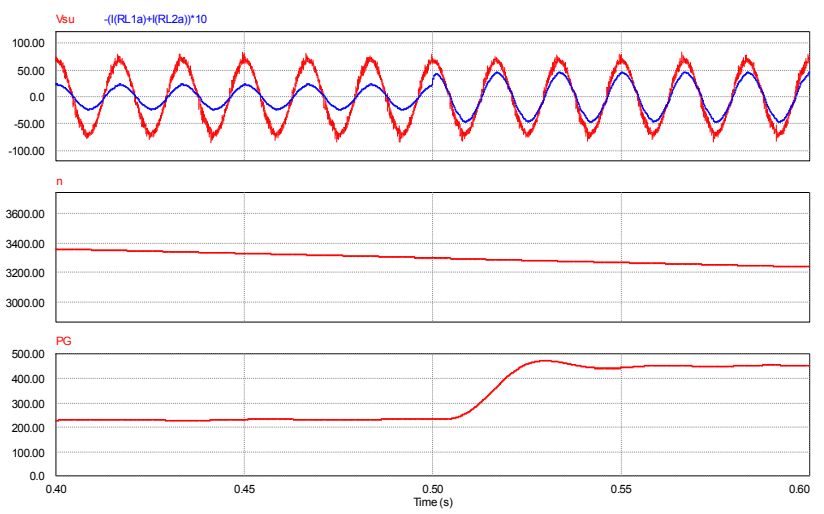

Figure 11. Energy supplying to load system from flywheel simulation

From Upper to Lower:

Load voltage and current,

Rotating speed of flywheel, Load power

Figure 11 shows the simulation results of operation mode (2) when the flywheel is supplying the energy to the islanded load. It indicates that the load voltage is kept constant when the load increases. The load current is doubled at $0.5 \mathrm{sec}$. The load voltage has only a little reduction. The rotating speed of the flywheel is continuously decreased because of the power supply.

\section{CONCLUSIONS}

We proposed emergency power supply using the induction generator with the flywheel.

Experimental results of start-up and steady state condition were shown. Simulation results of rotating speed change when the flywheel absorb and output the stored energy are also shown.

The control of VSC1 and VSC2 are still primitive and cannot have substantial performance in some condition. Further investigations are required to achieve it. 


\section{REFERENCES}

[1] K. Taniguchi, N. Kimura, " the induction power generation UPS system which regains slip electric power ", Transaction of IAS, IEE-Japan, Vol.114-D, 1994.12. (in Japanese).

[2] N. Kimura, K. Taniguchi, "Uninterrupted Power Supply using SlipPower Recovery Induction Generator", International Conference on Power Electronics and Drive Systems "PEDS'95", 1995.

[3] H. Morita, K. Taniguchi, N. Kimura, K. Taniguchi, " The Basic Study of Converter Control for Induction Generator with Flywheel", the H14 IEE-Japan annual meeting, 4-112, 2002.3 (in Japanese).

[4] H. Akagi, H. Sato, "Control and Performance of a Doubly-Fed Induction Machine Intended for a Flywheel Energy Storage System", IEEE Trans. On Power Electronics, Vol.17, No.1, 2002. 